\title{
EFEKTIVITAS PERAN SATUAN RESERSE NARKOBA POLRES BUKITTINGGI DALAM MENGATASI PENYALAGUNAAN NARKOTIKA
}

\author{
OKRIADI \\ Program Studi Pascasarjana Ilmu Hukum \\ Universitas Ekasakti Padang
}

\begin{abstract}
Narcotic is a substance or medicine that very important and needed to treat a certain disease. However, if misused or used not suitable with standard treatment will damage to personal or society especially young generation. Using of narcotic will make a big damage to the life and cultural values of a nation. Since October 2009, the government has approved the Law Number 35 Year 2009 about Narcotics. Based on this law, the Indonesian Police (Polri) changed the approach in eradicating narcotics. The Indonesian Police (Polri) is the front guard to fight the narcotic.

The problem in this study are: First, how is the role of Narcotic Detective Unit of Bukittinggi Police in embracing narcotic in the law field of Bukittinggi Police? Second, how is the effective of the role of Narcotic Detective Unit of Bukittinggi Police in embracing narcotic in the law field of Bukittinggi Police? The approach uses in this research is the normative as the main approach and juridical empiric approach as support. The techniques of collecting data uses are field study by interviewing for the primary data and library study for the secondary data. Then, the data analyzed qualitatively in descriptive analysis form. From the research results obtained several conclusions: First, the role of Narcotic Detective Unit of Bukittinggi Police in embracing narcotic in the law field of Bukittinggi Police is implemented in the preemptive, preventive, and repressive roles. Second, the implementation of the role of Narcotic Detective Unit of Bukittinggi Police in embracing narcotic in the law field of Bukittinggi Police has been effective. It is proved by many cases of narcotic finished by the role of Narcotic Detective Unit of Bukittinggi Police in embracing narcotic in the law field of Bukittinggi Police year 2015 - 2017 are year 2015 there were 47 cases with 63 suspected, year 2016 there were 48 cases with 69 suspected and year 2017 there were 48 cases with 59 suspected.
\end{abstract}

Kata Kunci : Efektivitas, Reserse Narkoba, Penyalagunaan Narkotika

\section{PENDAHULUAN}

Penyalagunaan narkotika di Indonesia sudah sangat mengkhawatirkan. Narkotikasendiri merupakan barang yang tidak lagi dikatakan barang haram yang susah untuk didapat, melainkan barang yang sangat mudah didapat karena kebutuhan sesaat sebagai efek candu dan kenikmatan tubuh penggunanya. Pecandu narkotika akan menghalalkan segala cara untuk mendapatkan barang haram ini karena narkotika memang suatu zat yang memiliki efek candu yang kuat bagi penggunanya dan efek ketergantungan yang luar biasa. Ketergantungan yang dialami pemakai narkotika ini jika tidak terealisasi, maka efek yang dialami adalah sakaw, yaitu keadaan di mana orang tersebut mengalami 
rasa gelisah atau gangguan psikis atau psikologis akibat kencanduan putau. ${ }^{1}$

Berdasarkan uraian di atas, maka permasalahan dalam penelitian ini dapat dirumuskansebagai berikut:

1. Bagaimanakah peran Satuan Reserse Narkoba Polres Bukittinggi dalam mengatasi penyalahgunaan narkotika di wilayah hukum Kepolisian Resor Bukittinggi?

2. Bagaimanakah efektivitas peran Satuan Reserse Narkoba Polres Bukittinggi dalam mengungkap kejahatan penyalahgunaan narkotika?

\section{KERANGKA TEORETIS}

Kata efektif berasal dari bahasa Inggris, yaitu effective yang berarti berhasil atau sesuatu yang dilakukan berhasil dengan baik. Kamus ilmiah popular mendefinisikan efektivitas sebagai ketetapan penggunaan, hasil guna atau menunjang tujuan. Efektivitas merupakan unsur pokok untuk mencapai tujuan atau sasaran yang ditentukan di dalam setiap organisasi, kegiatan ataupun program. Disebut efektif apabila tercapai tujuan ataupun sasaran seperti yang telah ditentukan.

Mengenai masalah pelaksanaan hukum adalah masalah bagaimana hukum ditegakkan atau disebut penegakan hukum. Sedangkan penegakan hukum adalah suatu proses untuk

${ }^{1}$ Heriady Willy, Berantas Narkoba Tak Cukup Hanya Bicara-(Tanya Jawab dan Opini),UII Press, Yogyakarta, 2005, hlm. 70 mewujudkan keinginan-keinginan hukum menjadi kenyataan, sehingga berfungsi untuk memelihara ketertiban juga berfungsi untuk mencapai tujuan hukum.

Penanggulangan kejahatan dengan menggunakan (hukum) pidana merupakan cara yang paling tua, setua peradaban manusia itu sendiri. Ada pula yang menyebutnya sebagai "older philosophy of crime control". Dilihat sebagai suatu masalah kebijakan, maka ada yang mempermasalahkan apakah perlu kejahatan ditanggulangi, dicegah atau dikendalikan, dengan menggunakan sanksi pidana. Untuk dapat menjalankan hukum pidana (substantif) perlu hukum yang dapat menjalankan ketentuan-ketentuan yang ada dalam hukum pidana (substantif) yaitu hukum formil atau hukum acara pidana. Hukum pidana sendiri dalam arti luas meliputi juga hukum subtantif/materiil dan hukum formil.

\section{METODE PENELITIAN}

Metode yang digunakan dalam penelitian ini adalah metode penelitian yang bersifat deskriptif analitis. Metode penelitian deskriptif analitis merupakan penelitian hukum yang dilakukan untuk memberikan data yang seteliti mungkin tentang manusia, keadaan atau gejala-gejala lainnya ataupun fenomena. Penelitian deskriptif sangat berguna untuk mempertegas sebuah hipotesis,

2 Muladi dan Barda Nawawi Arief, Teori-Teori dan Kebijakan Pidana, Alumni, Bandung, 1984, hlm. 149 
agar dapat membantu dalam memperkuat teori-teori lama, atau didalam kerangka mencoba merumuskan teori baru. ${ }^{3}$

Sumber data yang diperlukan dalam penelitian ini adalah sumber data sekunder dan data primer dengan metode pengumpulan data melalui studi pustaka, observasi dan wawancara. Data dianalisis dengan cara normatif kualitatif yakni menafsirkan dan menjabarkan data berdasarkan asas-asas hukum, norma hukum dan teori hukum.

Metode analisis yang digunakan dalam penelitian ini adalah metode analisis kualitatif. Metode analisis kualitatif merupakan tata cara penelitian yang menghasilkan data deskriptif, yaitu apa yang dinyatakan informan secara lisan atau tertulis.

\section{PEMBAHASAN}

Penanggulangan Penyalahgunaan Narkotika di Kepolisian Resor Bukittinggi

Upaya penanggulangan penyalahgunaan narkotika di wilayah hukum Polres Bukittinggi yang telah dilakukan oleh Satres Narkoba adalah sebagai berikut:

Upaya preemtif adalah upaya pencegahan yang dilakukan secara dini, antara lain mencakup pelaksanaan kegiatan penyuluhan yang bersifat dengan sasaran untuk memengaruhi faktor-faktor penyebab pendorong dan faktor peluang (faktor korelatif kriminogen) dari adanya kejahatan

\footnotetext{
${ }^{3}$ Soerjono Soekanto, Pengantar Penelitian Hukum, UI Press, Jakarta, 1984, hlm. 15
}

tersebut, sehingga akan tercipta suatu kondisi kesadaran kewaspadaan dan daya tangkal serta terbina dan terciptanya kondisi perilaku dan norma hidup bebas dari segala ancaman narkoba. Menyikapi maraknya penyalahgunaan narkotika, upaya preemtif yang dilakukan oleh Polres merupakan salah satu kegiatan operasional yang dilakukan oleh Satuan Narkoba Polres Bukittinggi.

Tindakan preventif merupakan pelaksanaan fungsi kepolisian yang diarahkan kepada upaya pencegahan terjadinya gangguan Kamtibmas. Adapun penanganan secara preventif yang dapat dilakukan adalah dengan meningkatkan kegiatan kepolisian. Dalam pencegahan masalah tindak pidana narkotika, pihak Satuan Reserse Narkoba melakukan Operasi Rutin Kepolisian dan Operasi Khusus Kepolisian.

Upaya represif dimulai ketika polisi mendapatkan informasi mengenai terjadinya tindak kejahatan. Sumber informasi tersebut bisa berasal dari laporan masyarakat, media massa, diketahui langsung oleh aparat, maupun data yang diberikan oleh intelijen kepolisian. Mengenai informasi yang berasal dari data intelijen kepolisian dan laporan masyarakat.

Peran Satuan Reserse Narkoba Polres Bukittinggi dalam Mengatasi Penyalagunaan Narkotika di Wilayah Hukum Kepolisian Resor Bukittinggi 
Perkembangan masyarakat itu disebabkan karena ilmu pengetahuan dan pola pikir masyarakat yang semakin maju. Masyarakat berusaha mengadakan pembaharuan-pembaharuan di segala bidang. Namun kemajuan teknologi tidak selalu berdampak positif, bahkan ada kalanya berdampak negatif. Maksudnya adalah dengan kemajuan teknologi juga ada peningkatan masalah kejahatan dengan menggunakan modus operandi yang canggih. Hal tersebut merupakan tantangan bagi aparat penegak hukum untuk mampu menciptakan penanggulangannya, khususnya dalam kasus narkotika dan obat-obatan terlarang.

Sedangkan tugas represif adalah tugas terbatas, kewenangannya dibatasi oleh KUHAP sehingga asasnya bersifat legalitas yang berarti semua tindakannya harus berlandaskan hukum. Bentuk pelaksanaan daripada tugas represif berupa tindakan penyelidikan, penggerebekan, penangkapan,penyidikan, investigasi sampai peradilannya.

Upaya preemtif adalah upaya pencegahan yang dilakukan secara dini, antara lain mencakup pelaksanaan kegiatan penyuluhan yang bersifat dengan sasaran untuk memengaruhi faktor-faktor penyebab pendorong dan faktor peluang (faktor korelatif kriminogen) dari adanya kejahatan tersebut, sehingga akan tercipta suatu kondisi kesadaran kewaspadaan dan daya tangkal serta terbina dan terciptanya kondisi perilaku dan norma hidup bebas dari segala ancaman narkoba. Menyikapi maraknya penyalahgunaan narkotika, upaya preemtif yang dilakukan oleh Polres merupakan salah satu kegiatan operasional yang dilakukan oleh Satuan Narkoba Polres Bukittinggi.

Tindakan preventif merupakan pelaksanaan fungsi kepolisian yang diarahkan kepada upaya pencegahan terjadinya gangguan Kamtibmas. Adapun penanganan secara preventif yang dapat dilakukan adalah dengan meningkatkan kegiatan kepolisian. Dalam pencegahan masalah tindak pidana narkotika, pihak Satuan Reserse Narkoba melakukan Operasi Rutin Kepolisian dan Operasi Khusus Kepolisian.

Upaya represif dimulai ketika polisi mendapatkan informasi mengenai terjadinya tindak kejahatan. Sumber informasi tersebut bisa berasal dari laporan masyarakat, media massa, diketahui langsung oleh aparat, maupundata yang diberikan oleh intelijen kepolisian. Mengenai informasi yang berasal dari data intelijen kepolisian dan laporan masyarakat.

\section{Efektivitas Peran Satuan Reserse Narkoba}

Polres Bukittinggi dalam Mengungkap

\section{Kejahatan Penyalahgunaan Narkotika}

Efektivitas hukum dalam menanggulangi tindak pidana narkotika sangat ditentukan oleh penegak hukum. Hal ini sesuai dengan pemikiran dari Achmad Ali mengatakan bahwa efektif tidaknya suatu 
aturan hukum secara umum tergantung pada optimal dan profesional tidaknya aparat penegak hukum untuk menegakkkan berlakunya aturan hukum tersebutmulai dari tahap pembuatannya, sosialisasinya, proses penegakan hukumnya yang mencakupi tahapan penemuan hukum (penggunaan penalaran hukum, interpretasi dan konstruksi), dan penerapannya terhadap suatu kasus konkret. Efektif atau tidaknya aturan hukum juga mensyaratkan adanya standar hidup sosio-ekonomi yang minimal di dalam masyarakat. ${ }^{4}$

1. Faktor Penegak Hukum

Hambatan dalam upaya penanggulangan dan pemberantasan narkotika, terjadi karena kurangnya sumber daya di tubuh Polri baik secara kualitas maupun secara kuantitas.

2. Faktor Sarana dan Fasilitas dalam Penegakan Hukum

Tindak pidana narkotika tidak lagi dilakukan secara perseorangan, melainkan melibatkan banyak orang yang secara bersama-sama, bahkanmerupakan satu sindikat yang terorganisasi dengan jaringan yang luas yang bekerja secara rapi dan sangat rahasia baik di tingkat nasional maupun internasional.

3. Faktor Masyarakat

${ }^{4}$ Zainuddin Ali, Filsafat Hukum, Sinar Grafika, Jakarta, 2010, hlm. 378
Upaya pembangunan tatanan hukum paling tidak didasarkan atas 3 (tiga) alasan.

4. Faktor Kebudayaan

Aspek kebudayaan merupakan suatu garis pokok tentang perikelakuan atau blueprint for behavior yang menetapkan peraturan-peraturan mengenai apa yang seharusnya dilakukan, apa yang selayaknya dilakukan dan seterusnya. ${ }^{5}$

\section{PENUTUP}

Berdasarkan hasil penelitian dan pembahasan serta analisis yang dilakukan diperoleh kesimpulan sebagai berikut:

Peran Satuan Reserse Narkoba Polres Bukittinggi dalam mengatasi penyalahgunaan narkotika di wilayah hukum Kepolisian Resor Bukittinggi diwujudkan dalam bentuk upaya preemtif, upaya preventifsertaupaya represif. upaya preemtif yaitu upaya pencegahan yang dilakukan secara dini, antara lain mencakup pelaksanaan kegiatan penyuluhan yang bersifat dengan sasaran. Sementara itu, upaya preventif merupakan pelaksanaan fungsi kepolisian yang diarahkan kepada upaya pencegahan terjadinya tindak pidana narkotika. adapun upaya represif merupakan upaya penindakan yang dimulai ketika polisi mendapatkan informasi mengenai terjadinya tindak kejahatan.

5 Soerjono Soekanto, Pokok-pokok Sosiologi Hukum, RajaGrafindo Persada, Jakarta, 2009, hlm. 204 
Pelaksanaan peran Satuan Reserse Narkoba Polres Bukittinggi dalam mengungkap kejahatan penyalahgunaan narkotika sudah berjalan dengan efektif. Hal tersebut dibuktikan dengan banyak kasus penyalahgunaan narkotika yang berhasil diungkap oleh Satuan Reserse Narkoba Polres Bukittinggi beserta jajarannya selama tahun 2015 - 2017 yakni tahun 2015 sebanyak 47 kasus dengan jumlah tersangka sebanyak 63 orang, tahun 2016 sebanyak 48 kasus dengan jumlah tersangka sebanyak 69 orang serta tahun 2017 sebanyak 48 kasus dengan jumlah tersangka sebanyak 59 orang.

\section{DAFTAR PUSTAKA}

\section{Buku-Buku}

Abdul Ghofur Anshori, Filsafat Hukum Sejarah, Aliran dan Pemaknaan, Gadjah Mada University Press, Yogyakarta, 2006.

Abdulkadir Muhammad, Etika Profesi Hukum, Citra Aditya Bakti, Bandung, 2006.

Abdul Manan, Aspek-aspek Pengubah Hukum, Kencana Prenada Media Goup, Jakarta, 2009.

Achmad Ali, Menguak Teori Hukum (Legal Theory) dan Teori Peradilan (JudicialPrudence) Termasuk Interpretasi Undang-undang (Legisprudence), Kencana Prenada Media Group, Jakarta, 2009.
Adrianus Meliala, Problema Reformasi Polri, Trio Repro, Jakarta, 2006.

Agung Kurniawan, Transformasi Pelayanan Publik, Raja Grafindo, Jakarta, 2005.

Andi Hamzah, Asas-asas Hukum Pidana, Rineka Cipta, Jakarta, 1994.

Antony Allot, The Limit of Law, Butterworth \& Co., London, 1980.

Arief Amrullah, Politik Hukum Pidana Dalam Perlindungan Korban kejahatan Ekonomi di Bidang Perbankan, Bayumedia, Jakarta, 2010.

Barda Nawawi Arief, Kebijakan Legislatif dalam Penanggulangan Kejahatan dengan Pidana Penjara, Balai Penerbitan Undip, Semarang, 1996.

Bernard L. Tanya, Yoan N. Simanjutak dan Markus Y. Hage, Teori Hukum Strategi Tertib Manusia Lintas Ruang dan Generasi, Genta Publishing, Yogyakarta, 2010.

Breth Anthony Hayward, Relationship between Employee Performance, Leaderships and Disicpline in South African Parastatal Organization, Ph.D. Thesis Disertation, Rhodes University, 2005.

Chairul Huda, Dari Tiada Pidana Tanpa Kesalahan Menuju Kepada Tiada Pertanggungjawaban Pidana Tanpa Kesalahan, Fajar Interpratama Offset, Jakarta, 2006. 
C.S.T Kansil dan Christine S.T. Kansil, Pokok-pokok Hukum Pidana Untuk Tiap Orang, Pradnya Paramita, Jakarta, 2004.

Dahlan Thaib, Jazim Hamidi dan Niecmatul Huda, Teori dan Hukum Konstitusi, RajaGrafindo Persada, Jakarta, 1999.

Eman Sulaeman, Delik Perzinahan Dalam Pembaharuan Hukum Pidana Indonesia, Walisongo Press, Semarang, 2008.

Gatot Supramono, Hukum Narkoba Indonesia, Djambatan, Jakarta, 2007.

Heriady Willy, Berantas Narkoba Tak Cukup

Hanya Bicara-(Tanya Jawab dan

Opini), UII Press, Yogyakarta, 2005.

Herbert Packer, The Limits of the Criminal

Sanction, Stanford University Press,

California.

Iman Syaukani dan A.Ahsin Thohari, Dasar-

Dasar Politik Hukum, RajaGrafindo

Persada, Jakarta, 2008.

Jimly Asshiddiqie, Konstitusi dan Konstitusionalisme Indonesia, Sinar Grafika, Jakarta, 2010.

Kunarto, Perilaku Organisasi Polisi, Cipta Manunggal, Jakarta, 1997.

Lili Rasjidi, Dasar-Dasar Filsafat Hukum, Alumni, Bandung, 2001.

Lili Rasjidi dan Ira Rasjidi, Dasar-Dasar Filsafat dan Teori Hukum, Citra Aditnya Bakti, Bandung, 2001.
Moh. Mahfud MD, Membangun Politik Hukum, Menegakkan Konstitusi, RajaGrafindo Persada, Jakarta, 2010.

Moh. Taufik Makarao, Tindak Pidana Narkotik, Ghalia Indonesia, Jakarta, 2003.

Muladi dan Barda Nawawi Arief, Teori-Teori Dan Kebijakan Pidana, Alumni, Bandung, 1992.

Otje Salman, Beberapa Aspek Sosiologi Hukum, Alumni, Bandung, 1989.

Roeslan Saleh, Beberapa Asas Hukum Pidana Dalam Perspektif, Aksara Baru, Jakarta, 1983.

Roscoe Pound, Tugas Hukum (Roescoe Pound II), diterjemahkan oleh Muhammad Radjab, Bhratara, Jakarta, 1965.

Satjipto Rahardjo, Sisi-sisi Lain dari Hukum

di Indonesia, PT. Gramedia Pustaka Utama, Jakarta, 2003.

Siswantoro Sunarso, Penegakan Hukum Psikotropika, dalam Kajian Sosiologi Hukum, PT. Raja Grafindo Persada, Jakarta, 2004.

Soedarto, Kapita Selekta Hukum Pidana, Alumni, Bandung, 1986.

Soedjono, Narkotika dan Remaja, Penerbit, Alumni, Bandung, 1985.

Soejono H.Abdurrahman, Metode Penelitian Hukum, Rineka Cipta, Jakarta, 1997.

Soerjono Soekanto, Suatu Tinjauan Sosiologi Hukum terhadap Masalah-Masalah Sosial, Alumni, Bandung, 1981. 
Soleman B. Taneko, Pokok-Pokok Studi hukum dalam Masyarakat, PT. Raja Grafindo Persada, Jakarta, 1993.

Pegawai, Gramedia Widiasarana Indonesia, Jakarta, 1994.

Sunyoto Munandar Azhar, Psikologi Industri dan Organisasi, UI Press, Jakarta, 2006.

Suparlan, Masalah dan Issue manajemen Kepolisia Negara RI dalam Era Reformasi, CV. Amalia Bakti Jaya, Jakarta, 2004.

Yuliandri, Asas-Asas Pembentukan Peraturan Perundang-Undangany yang Baik (Gagasan Pembentukan Undang-undang Berkelanjutan), PT. Grafindo Persada, Jakarta, 2009.

Zainuddin Ali, Filsafat Hukum, Sinar Grafika, Jakarta, 2010.

\section{Peraturan Perundang-Undangan}

Undang-Undang Dasar Negara Republik Indonesia Tahun 1945.

Undang-Undang Nomor 8 Tahun 1981 tentang Hukum Acara Pidana.

Undang - undang Nomor 2 Tahun 2002 tentang Kepolisian Negara Republik Indonesia

Undang - undang Nomor 35 Tahun 2009 tentang Narkotika sebagai pengganti Undang-Undang Nomor 22 Tahun 1997 tentang Narkotika.
Peraturan Pemerintah Nomor 58 Tahun 2010 tentang Peraturan Pelaksanaan KUHAP.

Peraturan Presiden Nomor 23 Tahun 2010 tentang Badan Narkotika Nasional.

Keputusan Presiden Nomor 116 Tahun 1999 tentang Badan Koordinasi Narkotika Nasional (BKNN).

Instruksi Presiden Nomor 3 Tahun 2002 tentang Penanggulangan Penyalahgunaan dan Peredaran Gelap Narkotika.

Peraturan Kapolri Nomor 23 Tahun 2010 tentang Susunan Organisasi dan Tata Kerja pada Tingkat Kepolisian Resor dan Kepolisian Sektor. 